\section{Schedule control in the rabbit}

WILLIAM R. SEWELL, ARTHUR L. YEHLE, THEODORE J. NEWSOM, JAMES F. MCCOY, and CHARLES J. LONG, Memphis State University, Memphis, Tenn. 38111

Operant responding for water reinforcement was investigated in three New Zealand albino rabbits. Performance of two rabbits under FR3, FR8, and FR95 schedules was similar to the performance of other organisms exposed to low- or high-value fixed-ratio reinforcement. The behavior of the third rabbit under an FI 1-min LH 5-sec schedule was characteristic of fixed-ratio performance. These data were compared with data obtained from other organisms.

As an experimental organism, the rabbit has largely been subject to research involving classical conditioning (Yehle, 1968; Bruner, 1967; Peel \& Yehle, 1969), sexual behavior (Rubin \& Azrin, 1967), or animal "hypnosis" (Klemm, 1966). Few experiments have been designed to assess operant performance of the rabbit.

Recently, Bruner (1967) has demonstrated that rabbits will press a lever for electrical stimulation of certain brain areas on a continuous-reinforcement (CRF) schedule. However, the rabbit's behavior on other schedules of reinforcement was not reported. Previous work in this laboratory (McCoy \& Sewell, 1969) has investigated stimulus control in the rabbit during operant discrimination, wherein a CRF schedule was in effect during the S+ period. The data suggest a similarity between the performance of rabbits, rats, and pigeons on a simple discrimination task.

The present experiment was designed to extend the previous findings with regard to the operant performance of the rabbit on schedules of reinforcement other than CRF or extinction.

\section{SUBJECTS}

The Ss were three experimentally naive white male New Zealand rabbits. Each rabbit was separately housed and allowed free access to food. The animals were water-deprived by maintaining them on $50 \mathrm{ml}$ of water, which was presented each day following their scheduled running time.

Fig. 1. Selected cumulative response records of FR3 performance for R1. Reinforcements are indicated by the pip marks on the record. to progressively increasing fixed-interval requirements as follows: FI 15 -sec for eight sessions, FI 30-sec for 20 sessions, and FI 1-min for 10 sessions. During the FI 1-min sessions, it was noticed that occasional long pauses were occurring, 80 a limited hold of $5 \mathrm{sec}$ (LH5) was added, and the FI 1-min LH 5-sec schedule remained in effect for 51 sessions.

The behavior of $\mathrm{R} 1$ was allowed to stabilize on the FR3 and then on the FR8 schedule, while the behavior of R2 and R3 was not allowed to stabilize until the last schedule in the series had been reached. The Ss were considered stable on the FR3, FR8, FR95, and FI 1-min LH 5-sec schedules when the session-to-session variability in rate was not greater than 10 responses per minute over six sessions. The overall number of sessions required to achieve stability was equivalent to other organisms used in investigations of these schedules of reinforcement (Ferster \& Skinner, 1957; Hearst, 1960; Felton \& Lyon, 1966; Cloar \& Melvin, 1968).

\section{RESULTS AND DISCUSSION}

Cumulative records of stable performance under the FR3, FR8, FR95, and FI 1-min LH 5-sec schedules are depicted in Figs. 1-4, respectively. Performance under the FR3 and FR8 schedules (Figs. 1 and 2) was characterized by linear rates, with little or no pause after reinforcement. During the FR8 schedule, R1 occasionally responded "through" the reinforcement, i.e., even though the reinforcement had been delivered, the rabbit continued to respond. Rates were 38.8 and 49.2 responses per minute for the FR3 and FR8 schedules, respectively.

Performance for R2 on FR95 is shown in Fig. 3, which depicts a high linear rate (124.5 responses per minute) throughout the session and a progressive increase in the pause after reinforcement over the session. These data an in agreement with those accumulated for the pigeon. Ferster \& Skinner (1957) found that a pause did not occur until the response requirement exceeded 40 . However, the longest pause for the rabbit was less than 2 min on the FR95 schedule, whereas Ferster and Skinner report pauses of greater than sessions, and FR95 was in effect for the remaining 20 . The last rabbit was exposed progressively increased from FR2 through FR10. For the next 10 sessions, R2 was exposed to two session blocks of FR 15 FR30, FR45, FR60, and FR70. An FR80
schedule was in effect for the next 10
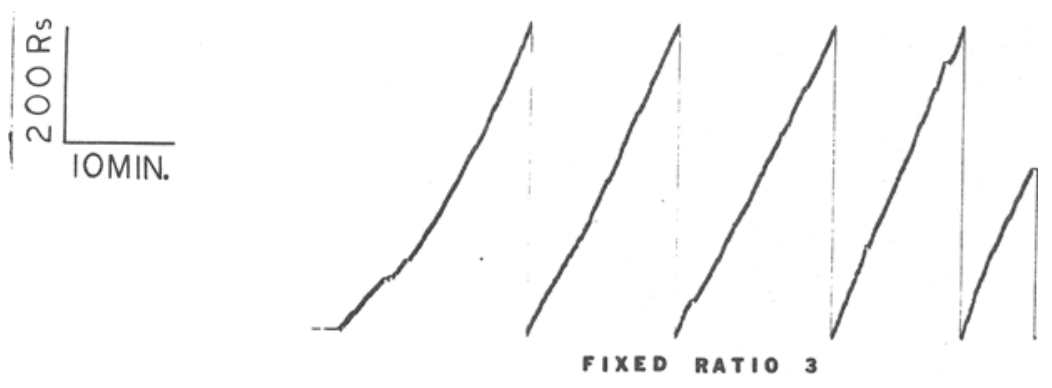

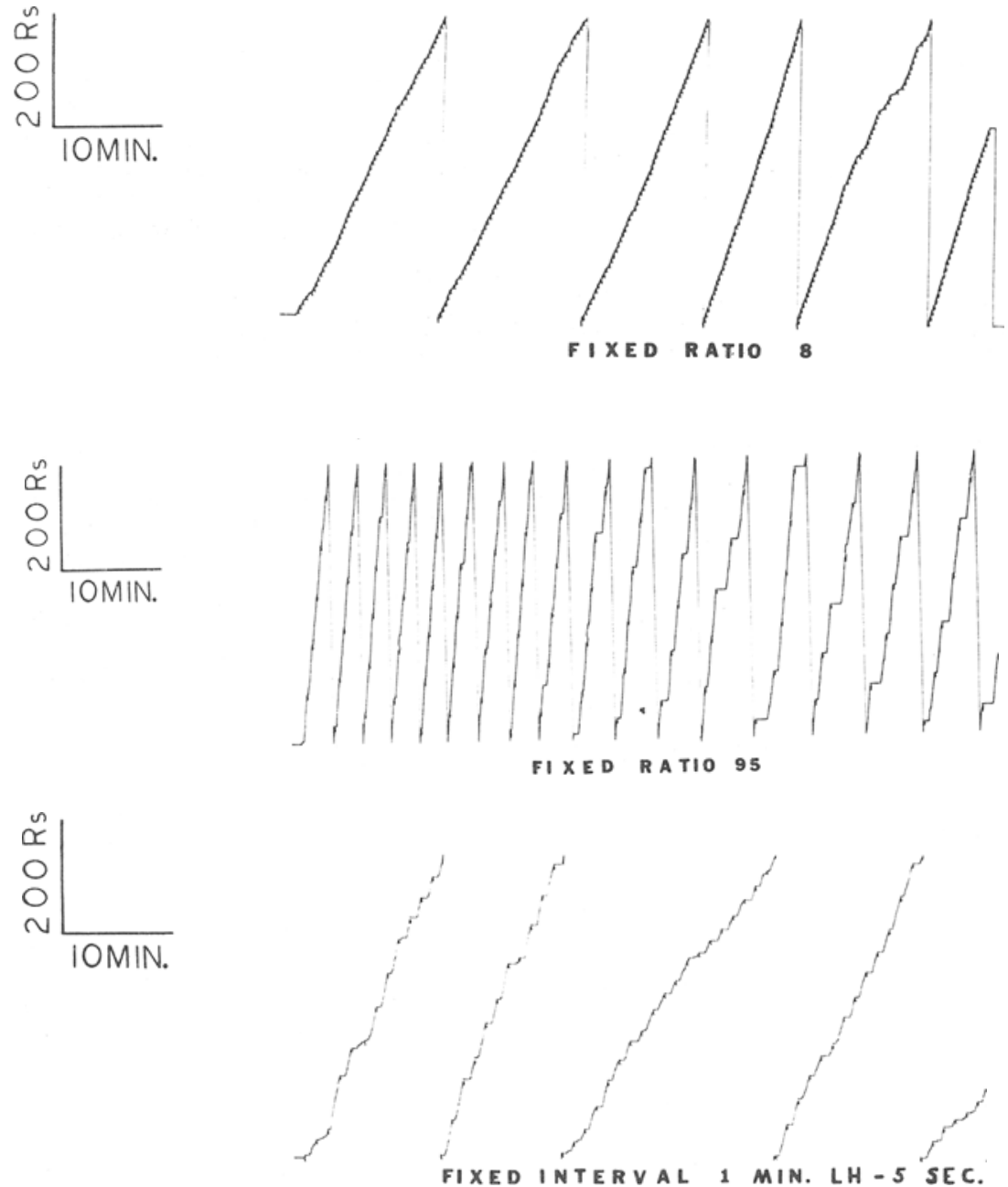

10 min on an FR 120 schedule

The cumulative record of R3's performance on the FI 1-min LH 5-sec schedule is shown in Fig. 4. Early in the session, a warmup effect is evident, wherein there is a period of acceleration that leads to the FI scallop that is characteristic of the remainder of the session. The overall rate is 34.2 responses per minute. In general, the performance of the rabbit is similar to that of the pigeon. The overall rate is nearly identical to the rate of one bird reported by Ferster \& Skinner (1957), which was also responding on an FI 1-min schedule. The performance of R3 differs from the performance obtained with other organisms, in that the scallops are not as smooth, and R3 frequently emitted a high-rate run to reinforcement after a pause. It is possible that these high-rate runs were produced by the limited hold contingency that had been in effect for 50 sessions at the time this record was taken. Hearst (1958) noted ratio-like behavior on fixed-interval schedules with limited holds.

The findings in this research, although
FIXED RATIO
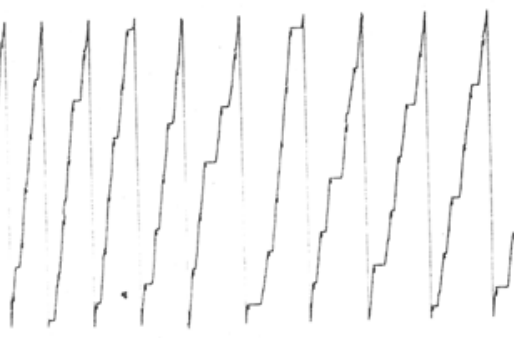

FIXED RATIO 95

Fig. 2. Selected cumulative response records of FR8 performance for R1. Reinforcements are indicated by the pip marks on the record.

Fig. 3. Selected cumulative response records for $R 2$ under an FR95 schedule. Reinforcements are indicated by pip marks on the record.

Fig. 4. Selected cumulative response records for R3 during an FI 1-min LH 5 -sec schedule. Reinforcements are indicated by pip marks on the record.

schedules. Journal of the Experimental Analysis of Behavior, 1968, 11, 187-190.

FELTON, M., \& LYON, D. O. The post-reinforcement pause. Journal of the Experimental Analysis of Behavior, 1966, 9, 131-134.

FERSTER, C. B. The use of the free operant in the analysis of behavior. Psychological Bulletin, 1953, 50, 263-274.

determined for a small number of Ss, extend the generality of behavioral principles to the rabbit and suggest that they can be used as experimental animals in physiological research where brain functions can be assessed by operant methodology. As an experimental animal, the rabbit has some of the same advantages as a pigeon (Ferster, 1953), e.g., a long life span (8-10 years) that allows a large number of successive manipulations and a well tailored response (the nosing response) that is extremely suitable for free-operant experimentation. This study demonstrates that a high rate of response can be generated in the rabbit which can vary over a wide range and is, therefore, more sensitive to manipulation.

\section{REFERENCES}

BRUNNER, A. Self-stimulation in the rabbit: An anatomical map of stimulation effects. Joumal of Comparative Neurology, 1967, 131, 615-629.

CLOAR, F.T., \& MELVIN, K. B. Performance of two species of quail on basic reinforcement
FERSTER, C. B., \& SKINNER, B. F. Schedules of reinforcement. New York: Appleton-Century-Crofts, 1957.

KLEMM, W. R. A method to encourage extensive study of animal hypnotic behavior. Journal of the Experimental Analysis of Behavior, 1966, 9,63-64.

HEARST, E. The behavioral effects of some temporal defined schedules of reinforcement. Journal of the Experimental Analysis of Behavior, 1958, 1, 45-55.

HEARST, E. Multiple schedules of time-correlated reinforcement. Journal of the Experimental Analysis of Behavior, 1960, 3, 49-62.

McCOY, J. F., \& SEWELL, W. R. Stimulus control in the rabbit. Paper read at the Southeastem Psychological Association, New Orleans, February 26, 1969.

PEEL, W, \& YEHLE, A. Differential effects of d-amphetamine in classical discrimination conditioning of rabbits. Psychonomic Science, $1969,14,210-211$.

RUBIN, H. B., \& AZRIN, N. H. Temporal patterns of sexual behavior in rabbits as determined by an automatic recording technique. Joumal of the Experimental Analysis of Behavior, 1967, 10, 219-231.

YEHLE, A. L. Divergences among rabbit response systems during three-tone classical discrimination conditioning. Joumal of Experimental Psychology, 1968, 77, 468-473. 